\title{
Involved-Field Radiotherapy for Advanced Hodgkin's Lymphoma
}

From the Netherlands Cancer Institute, Amsterdam (B.M.P.A., J.W.B.); the University Medical Center Nijmegen, Nijmegen, the Netherlands (J.M.M.R., R.W.M.M.); the National Cancer Institute, Aviano, Italy (U.T., R.B.); Erasmus University Medica Center, Rotterdam, the Netherlands (M.B.V., P.J.L., J.H.M., A.H.); Catharina Hospital Eindhoven, the Netherlands (M.L.M.L.); Máxima Medisch Centrum, Veldhoven, the Netherlands (J.J.K.); Institut Gustave Rous sy, Villejuif, France (P.C., T.G., A.P.); Institute of Oncology, Ljubljana, Slovenia (R.T. M.V.); Oncological Center Algemeen Ziekenhuis St. Jan, Brugge, Belgium (A.v.H. G.D.); University Hospital Gasthuisberg Leuven, Belgium (J.T.); University Hospital Antwerp, Edegem, Belgium (W.S.); Algemeen Ziekenhuis Middelheim, Antw erp, Belgium (K.D.B.); Leiden University Medical Center, Leiden, the Netherland (J.C.K.-N.); Centre Léon Bérard, Lyons, France (C.C.); Hôpital St. Antoine, Paris (M.A.); Institut Jules Bordet, Brussels, Belgium (D.B.); Institut Bergonié, Bordeaux, France (H.E.); Radiotherapeutisch Instituut Friesland, Leeuwarden, the Netherland (W.G.J.M.S.); Medisch Spectrum Twente, Enschede, the Netherlands (J.H.M.); University Medical Center Utrecht, Utrecht, the Netherlands (A.H.); and Centre François Baclesse, Caen, France (M.H.-A.). Address reprint requests to Dr. Aleman at the Department of Radiotherapy, Netherlands Cancer Institute, Plesmanlaan 121, 1066 CX Amsterdam, the Netherlands, or at b.aleman@nki.nl.

Drs. Aleman and Raemaekers contributed equally to the study.

N Engl J Med 2003;348:2396-406.

Copyright (c) 2003 Massachusetts Medical Society.

\author{
Berthe M.P. Aleman, M.D., John M.M. Raemaekers, M.D., Ph.D., \\ Umberto Tirelli, M.D., Ph.D., Roberto Bortolus, M.D., Ph.D., \\ Mars B. van 't Veer, M.D., Ph.D., Marnix L.M. Lybeert, M.D., JoJ. Keuning, M.D., Ph.D., \\ Patrice Carde, M.D., Ph.D., Théodore Girinsky, M.D., Ph.D., \\ Richard W.M. van der Maazen, M.D., Ph.D., Radka Tomšič, M.D., \\ Marjeta Vovk, M.D., Ph.D., Achilles van Hoof, M.D., Ph.D., Geertrui Demeestere, M.D., \\ Pieternella J. Lugtenburg, M.D., Ph.D., José Thomas, M.D., Ph.D., \\ Wilfried Schroyens, M.D., Ph.D., Koenraad De Boeck, M.D., \\ Johanna W. Baars, M.D., Ph.D., Johanna C. Kluin-Nelemans, M.D., Ph.D., \\ Christian Carrie, M.D., Malek Aoudjhane, M.D., Dominique Bron, M.D., Ph.D., \\ Houchingue Eghbali, M.D., Wilma G.J.M. Smit, M.D., \\ Jacobus H. Meerwaldt, M.D., Ph.D., Anton Hagenbeek, M.D., Ph.D., Antonella Pinna, \\ and Michel Henry-Amar, M.D., Ph.D., for the European Organization for Research \\ and Treatment of Cancer Lymphoma Group
}

ABSTRACT

BACKGROUND

The use of involved-field radiotherapy after chemotherapy for advanced Hodgkin's lymphoma is controversial.

METHODS

We randomly assigned patients with previously untreated stage III or IV Hodgkin's lymphoma who were in complete remission after hybrid chemotherapy with mechlorethamine, vincristine, procarbazine, prednisone, doxorubicin, bleomycin, and vinblastine (MOPP-ABV) to receive either no further treatment or involved-field radiotherapy. Radiotherapy consisted of $24 \mathrm{~Gy}$ to all initially involved nodal areas and 16 to $24 \mathrm{~Gy}$ to all initially involved extranodal sites. Patients in partial remission were treated with $30 \mathrm{~Gy}$ to nodal areas and 18 to $24 \mathrm{~Gy}$ to extranodal sites.

RESULTS

Of 739 patients, 421 had a complete remission; 161 of these patients were assigned to no further treatment, and 172 to involved-field radiotherapy. The median follow-up was 79 months. The five-year event-free survival rate was 84 percent in the group that did not receive radiotherapy and 79 percent in the group that received involved-field radiotherapy $(\mathrm{P}=0.35)$. The five-year overall survival rates were 91 and 85 percent, respectively $(\mathrm{P}=0.07)$. Among the 250 patients in partial remission after chemotherapy, the five-year event-free and overall survival rates were 79 and 87 percent, respectively.

\section{CONCLUSIONS}

Involved-field radiotherapy did not improve the outcome in patients with advancedstage Hodgkin's lymphoma who had a complete remission after MOPP-ABV chemotherapy. Radiotherapy may benefit patients with a partial response after chemotherapy. 
T

HE OUTCOME OF TREATMENT FOR ADvanced Hodgkin's lymphoma has improved dramatically over the past two decades. Cure rates of more than 70 percent are now possible ${ }^{1-10}$ with a hybrid regimen of mechlorethamine, vincristine, procarbazine, prednisone, doxorubicin, bleomycin, and vinblastine (MOPP-ABV); a regimen of doxorubicin, bleomycin, vinblastine, and dacarbazine (ABVD); or a regimen of bleomycin, etoposide, doxorubicin, cyclophosphamide, vincristine, procarbazine, and prednisone (BEACOPP).

The potential role of radiotherapy after the completion of chemotherapy in patients with advanced Hodgkin's lymphoma stems from the observations that relapses usually occur at initially involved sites and that radiotherapy lowers the rates of recurrence. ${ }^{11}$ The results of several randomized studies have, however, raised questions about the benefit of adjuvant radiotherapy.9,11-16 Moreover, a combination of chemotherapy and radiotherapy may increase the risks of late complications, especially second cancers and cardiovascular disease. ${ }^{17-21}$ These risks must be balanced against the risk of treatment failure, since patients who have no response to initial therapy or who have an early relapse are not likely to be cured by salvage treatment. ${ }^{22-24}$

A previous European Organization for Research and Treatment of Cancer Lymphoma Group trial in patients with advanced Hodgkin's lymphoma used a response-adapted strategy consisting of six cycles of chemotherapy instead of eight in patients who had a complete remission after four cycles. ${ }^{3}$ The assumption was that two additional cycles of chemotherapy would consolidate an early complete remission, provided that a total of six cycles were given. ${ }^{25}$ These considerations led to the present trial to determine whether radiotherapy reduces the relapse rate among patients with stage III or IV Hodgkin's lymphoma who have a complete remission after six to eight cycles of MOPP-ABV hybrid chemotherapy (considered the standard chemotherapy at the time the trial was designed).

METHODS

\section{PATIENTS}

Patients with previously untreated stage III or IV Hodgkin's lymphoma who were 15 to 70 years of age were eligible for the study. Ineligibility criteria were pathological stage IIIA with splenic involvement as the only site of infradiaphragmatic disease; severe cardiac, pulmonary, or metabolic disease; and a previous diagnosis of cancer (except for nonmelanoma skin tumors and cervical carcinoma in situ). All pathological specimens were to be reviewed, but this was not a criterion for eligibility. The protocol was submitted to and approved by the ethics committee of each participating center, and oral informed consent was required before enrollment.

\section{PRETREATMENT WORKUP}

The following studies were required on enrollment: physical examination, complete blood count, measurement of the erythrocyte sedimentation rate, serum biochemical tests, a chest film, computed tomography (CT) of the chest, ultrasonography of the liver and spleen, bipedal lymphangiography (or abdominal CT where available), and unilateral bone marrow biopsy. Liver biopsy, bone scanning, and gallium scintigraphy were performed if indicated but were not required. After four cycles of chemotherapy, all examinations that had initially abnormal results (including bone marrow biopsy) were repeated.

Bulky disease was defined as a mass of at least $10 \mathrm{~cm}$ (largest diameter) or a bulky mediastinum (a ratio of the mediastinum to the thorax of at least 0.35 at the level of T5 through T6 while the patient was standing). ${ }^{26}$ Complete remission was defined as the disappearance of all disease-related symptoms and measurable lesions, including normalization of blood values and findings on radiologic examination and bone marrow-biopsy specimens. ${ }^{27}$

\section{CHEMOTHERAPY}

MOPP-ABV hybrid chemotherapy was administered to all patients in the following doses: mechlorethamine, $6 \mathrm{mg}$ per square meter of body-surface area given intravenously on day 1 ; vincristine, $1.4 \mathrm{mg}$ per square meter (maximal dose, $2 \mathrm{mg}$ ) given intravenously on day 1 ; procarbazine, $100 \mathrm{mg}$ per square meter given orally on days 1 through 7; prednisone, $40 \mathrm{mg}$ per square meter given orally on days 1 through 14; doxorubicin, $35 \mathrm{mg}$ per square meter given intravenously on day 8; bleomycin, $10 \mathrm{mg}$ per square meter given intramuscularly or intravenously on day 8; and vinblastine, $6 \mathrm{mg}$ per square meter given intravenously on day 8 . Chemotherapy was given every 28 days for a total of six to eight cycles.

Patients were evaluated after four cycles of chemotherapy (Fig. 1). Those with progressive disease or no change in their condition were excluded from the study. All other patients received two additional 


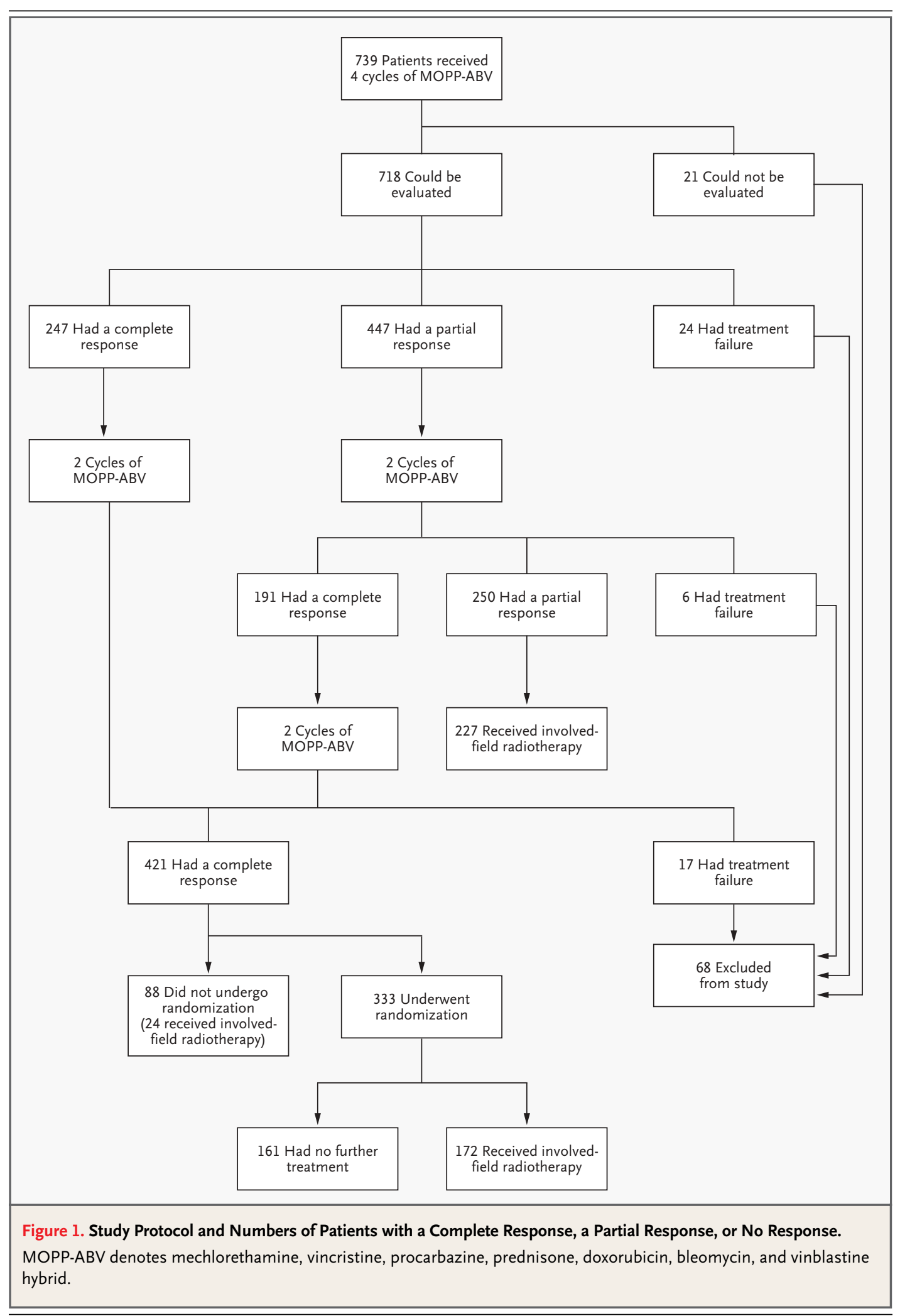


cycles of MOPP-ABV chemotherapy. Patients who were in complete remission after four cycles and who remained in complete remission after six cycles (early complete remission) were randomly assigned to receive no further treatment or involved-field radiotherapy. Patients who were in partial remission after four cycles and who were in complete remission after six cycles (late complete remission) were given two additional cycles of chemotherapy before undergoing randomization. Patients who remained in partial remission after six cycles stopped receiving chemotherapy and were treated with involved-field radiotherapy.

\section{NVOLVED-FIELD RADIOTHERAPY}

Patients in complete remission received 24 Gy of radiation to nodal regions; those in partial remission received $30 \mathrm{~Gy}$ (with a boost of 4 to $10 \mathrm{~Gy}$ if needed) in fractions of 1.5 to $2.0 \mathrm{~Gy}$. The spleen was included in the radiation field when the paraaortic nodes were involved. If the spleen was involved in the absence of known paraaortic node disease, the radiation fields encompassed both the spleen and the paraaortic nodes. If there was lung involvement initially, a dose of 16 Gy was prescribed after a complete remission, and a dose of $18 \mathrm{~Gy}$ was prescribed after a partial remission with a localized boost of 4 to $10 \mathrm{~Gy}$ when necessary. If the liver was involved, 20 Gy of radiation was given, and if bone was involved, a dose of $24 \mathrm{~Gy}$ was given to affected areas (with a boost of $10 \mathrm{~Gy}$ when necessary).

The dose was defined according to the guidelines of report 29 of the International Commission on $\mathrm{Ra}$ diation Units and Measurements. ${ }^{28}$ Involved-field radiotherapy started within six to eight weeks after the first day of the last cycle of chemotherapy and was administered in one to three courses, depending on the extent of the original involvement.

\section{STATISTICAL ANALYSIS}

The primary objective of the study was to determine whether adjuvant radiotherapy improved three-year relapse-free survival in patients who had a complete remission after six to eight cycles of MOPP-ABV. Secondary end points were event-free survival and overall survival.

Relapse-free survival was calculated from the date of assessment of complete remission (after four or six cycles of chemotherapy) to the date of the first relapse, the date of the last examination, the date of death, or June 1, 2002, whichever came first. Eventfree survival was calculated for all patients from the first day of chemotherapy to the date of the first event (treatment failure, relapse, or death from any cause), the date of the last examination, or June 1 , 2002, whichever came first. Overall survival was calculated from the first day of chemotherapy to the date of death, the date of the last examination, or June 1, 2002, whichever came first. The time to the development of a second cancer was calculated from the first day of chemotherapy to the date on which the second cancer was diagnosed, the date of death, the date of the last examination, or June 1 , 2002, whichever came first. The cumulative probability of a second cancer was calculated as 1 minus the probability of survival without the development of a second cancer.

Relapse-free survival, event-free survival, overall survival, and the cumulative probability of a second cancer were estimated according to the KaplanMeier method, and the rates in each group were compared with use of the log-rank test. Ninety-five percent confidence intervals for the rates were estimated with use of the method of Rothman and Boice. ${ }^{29}$ All analyses were performed according to the intention-to-treat principle. Two-sided tests were used in reporting the results. Stata statistical software was used to analyze data. ${ }^{30}$

Assuming a rate of complete remission of 70 percent and a three-year relapse-free survival rate of 80 percent after chemotherapy with MOPP-ABV, we needed to enroll 321 patients who were in complete remission and who had data that could be evaluated, in order for the study to have the power to demonstrate a 10 percent increase in survival (i.e., 90 percent vs. 80 percent) after adjuvant involvedfield radiotherapy ( $\alpha=0.05$ and $\beta=0.20$ by the logrank test and a one-sided test).

Forty-two cooperating centers in Belgium, France, Italy, the Netherlands, Poland, Portugal, and Slovenia participated. Registration, randomization, and data collection were performed at the Department of Biostatistics and Epidemiology, Institut Gustave Roussy, Villejuif, France. Randomization was stratified according to the center, and treatment assignments were provided by telephone or fax machine. Data were stored with use of a specific datamanagement program (PIGAS) developed at the Institut Gustave Roussy. ${ }^{31}$ Data were updated on June 1, 2002. The median follow-up period was 79 months. 


\begin{tabular}{|c|c|c|c|c|c|c|}
\hline \multicolumn{7}{|l|}{ Table 1. Characteristics of the Patients.* } \\
\hline Characteristic & $\begin{array}{c}\text { Total } \\
(\mathrm{N}=739)\end{array}$ & $\begin{array}{c}\text { No } \\
\text { Radiotherapy } \\
(\mathrm{N}=161)\end{array}$ & $\begin{array}{l}\text { mplete Remissi } \\
\text { Radiotherapy } \\
\qquad(\mathrm{N}=172)\end{array}$ & $\begin{array}{l}\text { Not } \\
\text { Randomized } \\
\quad(\mathrm{N}=88)\end{array}$ & $\begin{array}{l}\text { Partial } \\
\text { Remission } \\
(\mathrm{N}=250)\end{array}$ & $\begin{array}{l}\text { No Change, } \\
\text { Progression, Death, } \\
\text { or Could Not Be } \\
\text { Evaluated } \\
(\mathrm{N}=68)\end{array}$ \\
\hline $\begin{array}{l}\text { Age }-\mathrm{yr} \\
\text { Median } \\
\text { Range }\end{array}$ & $\begin{array}{c}33 \\
14-71\end{array}$ & $\begin{array}{l}32 \\
15-70\end{array}$ & $\begin{array}{c}36 \\
14-70\end{array}$ & $\begin{array}{c}34 \\
16-70\end{array}$ & $\begin{array}{l}30 \\
15-70\end{array}$ & $\begin{array}{c}44 \\
15-71\end{array}$ \\
\hline Male:female ratio & $1.79: 1$ & $1.73: 1$ & $1.77: 1$ & $1.67: 1$ & $1.66: 1$ & $3.00: 1$ \\
\hline $\begin{array}{l}\text { Site of disease - no. (\%) } \\
\text { Supradiaphragmatic } \\
\text { Infradiaphragmatic } \\
\text { Both }\end{array}$ & $\begin{aligned} 106(14) \\
18(2) \\
615(83)\end{aligned}$ & $\begin{aligned} & 19(12) \\
& 2(1) \\
& 140(87)\end{aligned}$ & $\begin{aligned} 23 & (13) \\
5 & (3) \\
144 & (84)\end{aligned}$ & $\begin{aligned} 14 & (16) \\
5 & (6) \\
69 & (78)\end{aligned}$ & $\begin{aligned} 44 & (18) \\
3 & (1) \\
203 & (81)\end{aligned}$ & $\begin{aligned} & 6(9) \\
& 3(4) \\
& 59(87)\end{aligned}$ \\
\hline $\begin{array}{l}\text { Stage - no. (\%) } \\
\text { IIIA } \\
\text { IIIB } \\
\text { IVA } \\
\text { IVB }\end{array}$ & $\begin{array}{r}191(26) \\
238(32) \\
96(13) \\
214(29)\end{array}$ & $\begin{array}{l}46(29) \\
50(31) \\
20(12) \\
45(28)\end{array}$ & $\begin{array}{l}46(27) \\
61(35) \\
19(11) \\
46(27)\end{array}$ & $\begin{array}{l}14(16) \\
26(30) \\
16(18) \\
32(36)\end{array}$ & $\begin{array}{l}77(31) \\
74(30) \\
32(13) \\
67(27)\end{array}$ & $\begin{aligned} & 8(12) \\
& 27(40) \\
& 9(13) \\
& 24(35)\end{aligned}$ \\
\hline $\begin{array}{l}\text { Mediastinal involvement - no. (\%) } \\
\text { Bulky mediastinum } †\end{array}$ & $\begin{array}{l}598(81) \\
208(35)\end{array}$ & $\begin{array}{r}132(82) \\
29(22)\end{array}$ & $\begin{array}{r}139(81) \\
42(30)\end{array}$ & $\begin{array}{l}65(74) \\
22(34)\end{array}$ & $\begin{array}{r}217(87) \\
96(44)\end{array}$ & $\begin{array}{l}45(66) \\
19(42)\end{array}$ \\
\hline Bulky disease - no. (\%) & $311(42)$ & $55(34)$ & $63(37)$ & $33(38)$ & $127(51)$ & $33(49)$ \\
\hline $\begin{array}{l}\text { No. of extranodal sites of disease in pa- } \\
\quad \text { tients with stage IV - no. (\%) } \\
\begin{array}{l}1 \\
2 \\
\geq 3\end{array}\end{array}$ & $\begin{array}{r}310 \\
203(65) \\
75(24) \\
32(10)\end{array}$ & $\begin{array}{l}65 \\
43(66) \\
17(26) \\
5(8)\end{array}$ & $\begin{array}{l}65 \\
40(62) \\
19(29) \\
6(9)\end{array}$ & $\begin{array}{c}48 \\
32(67) \\
12(25) \\
4(8)\end{array}$ & $\begin{array}{l}99 \\
67(68) \\
21(21) \\
11(11)\end{array}$ & $\begin{array}{r}33 \\
21(64) \\
6(18) \\
6(18)\end{array}$ \\
\hline $\begin{array}{l}\text { Extranodal locations } \\
\text { Lungs } \\
\text { Liver } \\
\text { Bone } \\
\text { Bone marrow }\end{array}$ & $\begin{array}{r}132(43) \\
77(25) \\
57(18) \\
83(27)\end{array}$ & $\begin{array}{l}24(37) \\
13(20) \\
13(20) \\
23(35)\end{array}$ & $\begin{array}{l}24(37) \\
18(28) \\
13(20) \\
22(34)\end{array}$ & $\begin{array}{r}19(40) \\
13(27) \\
6(12) \\
18(38)\end{array}$ & $\begin{array}{l}54(55) \\
18(18) \\
19(19) \\
14(14)\end{array}$ & $\begin{array}{r}11(33) \\
15(45) \\
6(18) \\
6(18)\end{array}$ \\
\hline Albumin $<40 \mathrm{~g} /$ liter — no./total no. (\%) & $297 / 596(50)$ & $65 / 130(50)$ & $67 / 136(49)$ & $41 / 72(57)$ & $88 / 203(43)$ & $36 / 55(65)$ \\
\hline $\begin{array}{l}\text { Histologic review - no. (\%) } \\
\text { Lymphocyte predominant } \\
\text { Nodular sclerosis } \\
\text { Mixed cellularity } \\
\text { Hodgkin's lymphoma of unspecified } \\
\text { subtype } \\
\text { Non-Hodgkin's lymphoma } \\
\text { Diagnosis of Hodgkin's lymphoma } \\
\text { uncertain }\end{array}$ & $\begin{array}{c}660 \\
12(2) \\
516(78) \\
98(15) \\
1(<1) \\
20(3) \\
13(2)\end{array}$ & $\begin{array}{c}144 \\
2(1) \\
112(78) \\
26(18) \\
0 \\
1(1) \\
3(2)\end{array}$ & $\begin{array}{c}157 \\
3(2) \\
117(75) \\
28(18) \\
0 \\
6(4) \\
3(2)\end{array}$ & $\begin{array}{c}74 \\
1(1) \\
54(73) \\
14(19) \\
0 \\
4(5) \\
1(1)\end{array}$ & $\begin{array}{c}228 \\
2(1) \\
196(86) \\
21(9) \\
1(1) \\
5(2) \\
3(1)\end{array}$ & $\begin{array}{l}57 \\
4(7) \\
37(65) \\
9(16) \\
0 \\
4(7) \\
3(5)\end{array}$ \\
\hline $\begin{array}{l}\text { Overall duration of treatment }- \text { mo } \\
\text { Median } \\
\text { Range }\end{array}$ & $\begin{array}{r}8.0 \\
1-19\end{array}$ & $\begin{array}{r}6.0 \\
3-11\end{array}$ & $\begin{array}{r}9.0 \\
5-19\end{array}$ & $\begin{array}{r}7.5 \\
5-14\end{array}$ & $\begin{array}{r}9.0 \\
5-16\end{array}$ & $\begin{array}{c}4.0 \\
1-10\end{array}$ \\
\hline
\end{tabular}

* Because of rounding, percentages may not total 100.

$\dagger$ Bulky mediastinum was defined, in patients with mediastinal involvement, as a ratio of mediastinum to thorax of at least 0.35 at the level of T5 through T6 while the patient was standing. ${ }^{26}$

$\uparrow$ Bulky disease was defined as a mass of at least $10 \mathrm{~cm}$ (largest diameter) or a bulky mediastinum.

$\int$ The overall duration of treatment was defined as the time from the start of chemotherapy to the start of the last chemotherapy cycle plus one month or to the end of the radiotherapy course among patients who received involved-field radiotherapy. 


\section{RESULTS}

CLINICAL CHARACTERISTICS AND RESPONSE TO CHEMOTHERAPY

From September 1989 to April 2000, a total of 739 patients were enrolled (Fig. 1). Table 1 shows the characteristics of the patients. The diagnosis of Hodgkin's lymphoma was confirmed in 627 of the 660 reviewed cases. Of the 33 patients with unconfirmed cases, the diagnosis of Hodgkin's lymphoma was uncertain in 13 and excluded in 20 (including 14 patients with non-Hodgkin's lymphoma). These 20 patients were equally distributed among the five subgroups of patients.

Of the 739 patients who received chemotherapy, 421 (57 percent) had a complete remission, 250 (34 percent) had a partial remission, 7 had no change, 26 had progressive disease, 14 died during therapy, and 21 could not be evaluated (Fig. 1 and Table 1). Of the 208 patients with bulky mediastinal disease, 93 (45 percent) had a complete remission and 96 (46 percent) had a partial remission. Among patients without bulky mediastinal disease, these proportions were 62 percent and 30 percent, respectively $(\mathrm{P}<0.001)$. Sixty-seven percent of the patients received six cycles of chemotherapy, and 26 percent received eight cycles; 7 percent stopped receiving chemotherapy because of progressive disease or poor tolerance.

Among the 421 patients in complete remission, 161 were randomly assigned to receive no radiotherapy and 172 to receive involved-field radiotherapy. The two groups had similar clinical characteristics (Table 1). Eighty-eight patients in complete remission did not undergo randomization because of the patient's refusal in 38 cases, the physician's refusal in 32 cases, a protocol violation in 16 cases, and unspecified reasons in 2 cases. Twenty-four of these 88 patients received radiotherapy, and 64 had no further treatment.

\section{ACUTE TOXICITY}

During or after chemotherapy, grade 3 (moderate) or grade 4 (severe) hematologic toxicity developed in 48 to 60 percent of patients, depending on the number of cycles of chemotherapy given; eight patients died of sepsis. Grade 3 or 4 radiation-related hematologic toxicity occurred in 16 percent of patients and was significantly more likely to occur in patients with previous severe toxicity due to chemotherapy than in those without such a history $(\mathrm{P}=0.01)$. Grade 3 or 4 radiation-related pulmo- nary toxicity occurred in three patients. No deaths were related to acute toxicity of radiotherapy.

\section{OUTCOME AMONG PATIENTS}

IN COMPLETE REMISSION

After a median follow-up of 79 months, the relapsefree survival rates and event-free survival rates (Fig. 2) were similar among patients in complete remission who did not receive radiotherapy and patients in complete remission who received involved-field radiotherapy. There was no significant difference between the two groups in overall survival (hazard ratio, $0.57 ; 95$ percent confidence interval, 0.31 to 1.06; $\mathrm{P}=0.07): 10$ percent of the patients who did not receive radiotherapy died, as compared with 16 percent of those who received involved-field radiotherapy. Overall, 14 percent of patients had relapses. The relapses were confined to originally involved sites in 11 of 24 patients who did not receive radiotherapy and in 6 of 22 patients who received involved-field radiotherapy.

\section{OUTCOME AMONG PATIENTS WHO DID NOT UNDERGO RANDOMIZATION}

The event-free and overall survival rates among patients who were not randomly assigned to a treatment but who had a complete or partial remission after chemotherapy were similar to those among patients who underwent randomization (Fig. 3 and

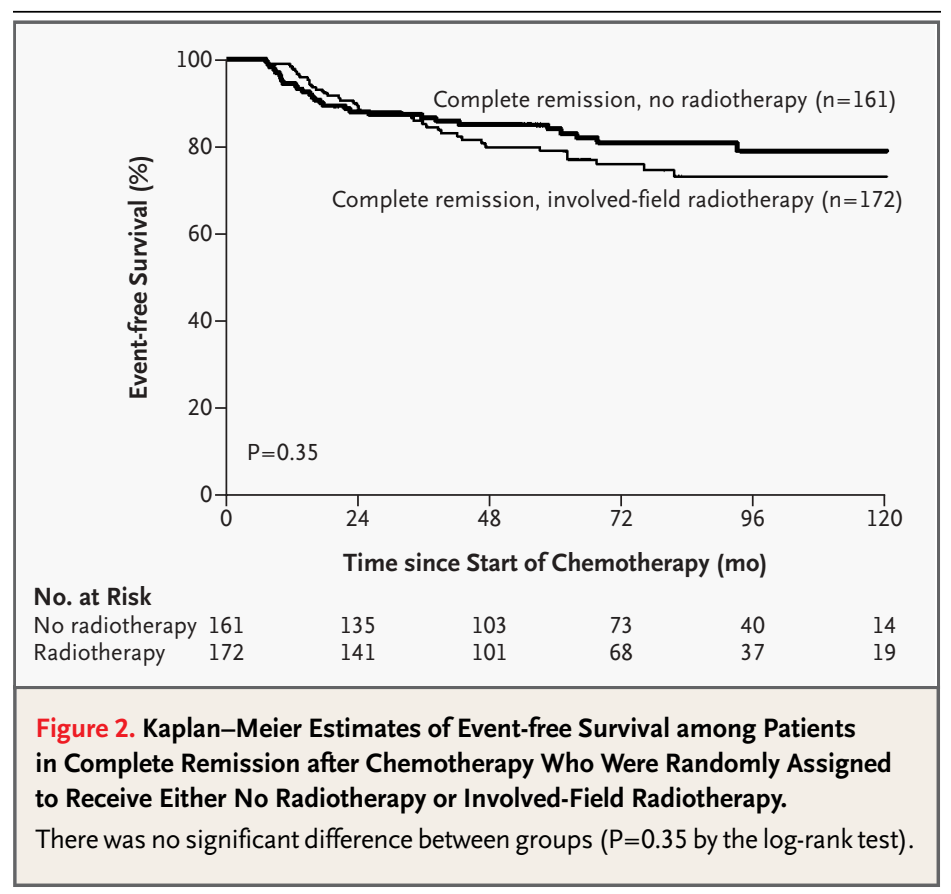




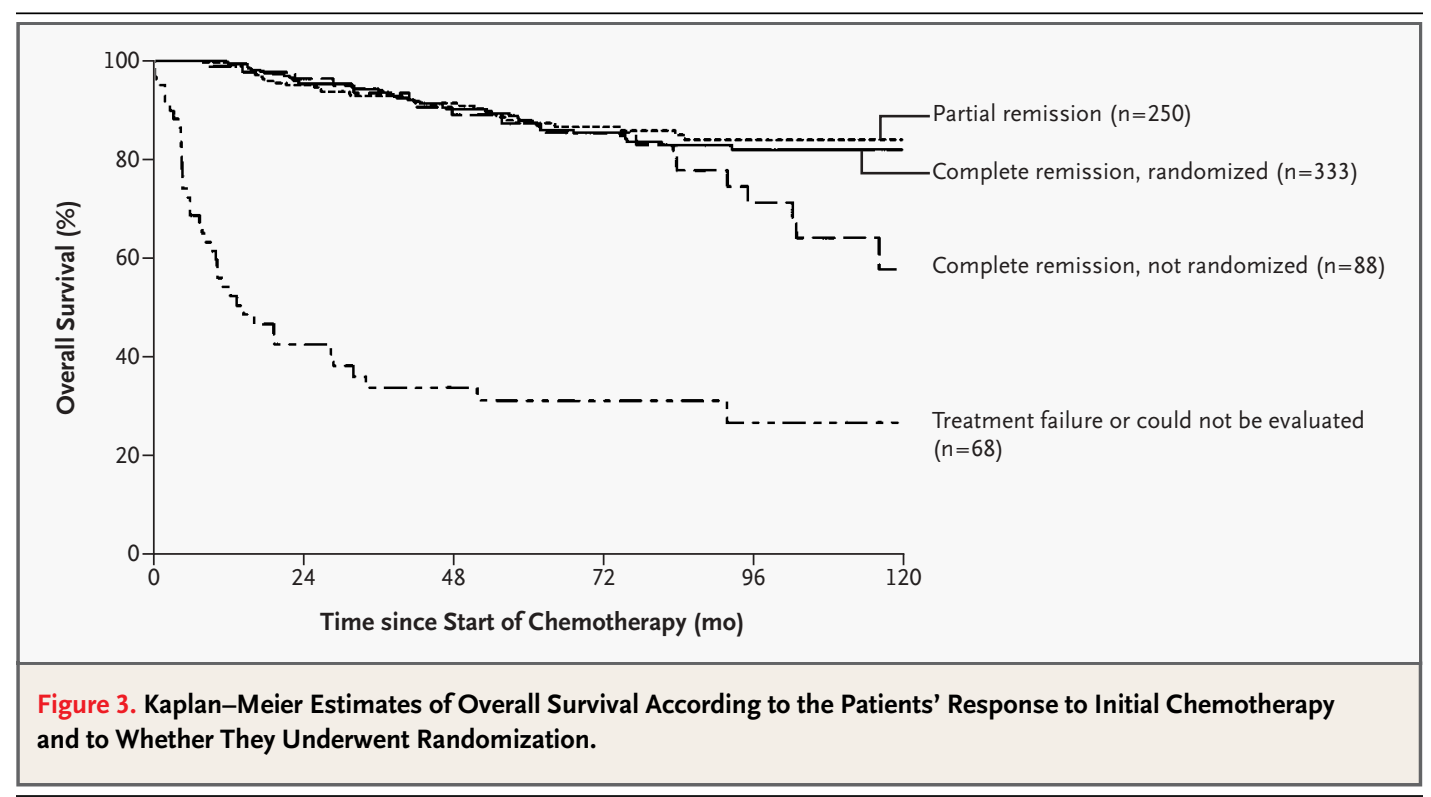

Table 2). Among such patients, the main causes of death were progressive disease and second cancers. Patients in whom MOPP-ABV treatment failure occurred or who could not be evaluated had a very poor outcome (Fig. 3 and Table 2).

\section{EFFECT OF PATHOLOGICAL REVIEW}

Among the 577 patients with a confirmed diagnosis of Hodgkin's lymphoma and a complete or partial response to chemotherapy, the five-year event-free and overall survival rates were 80 percent and 88 percent, respectively, as compared with 59 percent $(\mathrm{P}=0.02)$ and 65 percent $(\mathrm{P}=0.008)$, respectively, among the 16 patients with a complete or partial response who were found not to have Hodgkin's lymphoma after a pathological review.

\section{SECOND CANCERS}

A second cancer developed 9 to 112 months after the initiation of treatment in 6 patients in the group that did not receive radiotherapy and in 15 patients in the group that received involved-field radiotherapy; the five-year cumulative rates of second cancers were 4.0 percent and 7.8 percent, respectively $(\mathrm{P}=0.05)$ (Table 2$)$. In the other groups, the five-year cumulative rates of second cancers approached that among patients with a complete remission who were assigned to receive no radiotherapy. Of the 15 cases of acute leukemia or myelodysplasia, which occurred 10 to 99 months after the initiation of treatment, 13 developed in patients who were irradi- ated (including one patient who received radiation for a relapse).

\section{I SCUSSIO N}

The objective of this trial was to determine whether radiotherapy to all initially involved areas reduces the relapse rate among patients with stage III or IV Hodgkin's lymphoma who have a complete remission after MOPP-ABV chemotherapy. Our randomized trial involving 333 patients in complete remission failed to show that radiotherapy increases event-free or overall survival. These results underline the effectiveness of modern chemotherapy. Whereas a meta-analysis ${ }^{6}$ suggested that chemotherapy alone is sufficient treatment provided that eight cycles are administered, our findings indicate that six to eight cycles of MOPP-ABV produce very good results.

In the Southwest Oncology Group's randomized trial of involved-field radiotherapy, the 49 percent of patients who had a complete response after six cycles of nitrogen mustard, vincristine, prednisone, bleomycin, doxorubicin, and procarbazine (MOPBAP) were randomly assigned to receive involvedfield radiotherapy or no further treatment. ${ }^{14}$ No overall benefit from radiotherapy was observed; in patients with bulky, nodular sclerosing Hodgkin's lymphoma, however, the relapse-free survival rate was significantly higher after involved-field radiotherapy. A possible explanation for the difference 


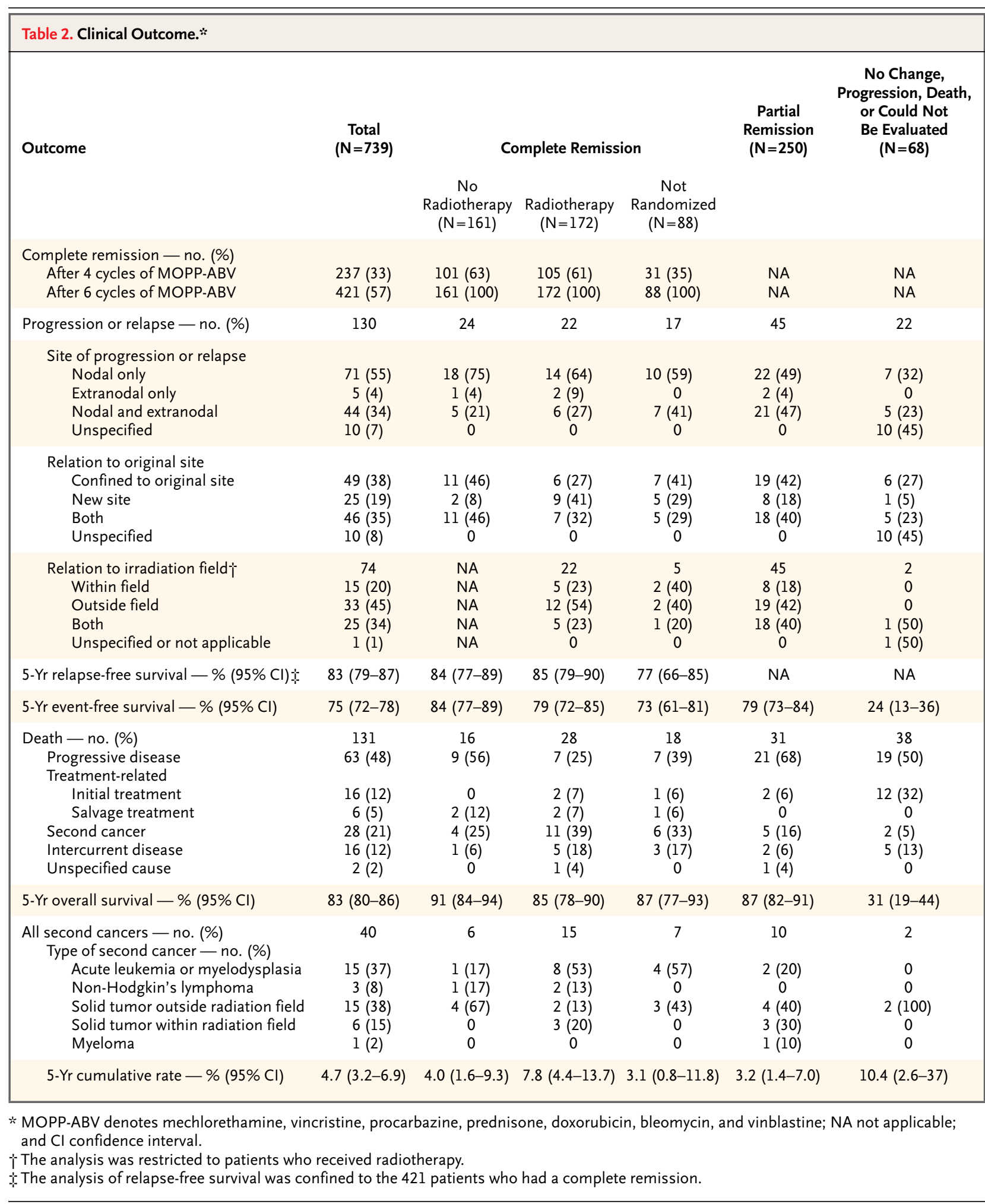


between these results and ours is that in the Southwest Oncology Group study the number of cycles of chemotherapy was not changed if there was a response. Alternatively, MOPP-ABV chemotherapy may be a more effective regimen than the MOP-BAP regimen, reducing the potential advantage of radiotherapy.

In the German Hodgkin's Study Group trial, patients with intermediate stages of Hodgkin's lymphoma who were in complete remission after chemotherapy were assigned to receive one additional cycle of chemotherapy (49 patients) or $20 \mathrm{~Gy}$ of involved-field radiotherapy (51 patients). ${ }^{13}$ There was no significant difference in outcome between the two groups. The Groupe d'Études des Lymphomes de l'Adulte has recently reported the results of a randomized trial comparing two additional cycles of doxorubicin-containing chemotherapy with total or subtotal nodal irradiation in patients with a complete or good partial remission of stage IIIB or IV Hodgkin's lymphoma. Although the radiotherapy was more extensive and the dose (30 Gy) was higher than the one we used, the outcome was similar in the two groups. ${ }^{9}$

These randomized trials highlight the importance of a chemotherapy-induced complete remission. The determination of complete remission is cumbersome, however, because it is difficult to discriminate between active disease and residual fibrosis. In our study, the outcome among patients with a partial response who received involved-field radiotherapy was similar to that among patients who were considered to be in complete remission after chemotherapy. However, a substantial proportion of our patients identified as having a partial response may actually have been in complete remission and may not have needed radiotherapy. In some studies, a partial remission after adequate first-line chemotherapy is considered an adverse prognostic factor, and immediate second-line chemotherapy, includ- ing high-dose regimens, is advised. ${ }^{9}$ Our results suggest that such intensification of treatment is unnecessary.

After a median follow-up of more than six years, patients who received radiotherapy after a complete remission had a higher rate of death from causes other than Hodgkin's lymphoma than did patients who did not receive radiotherapy. The five-year cumulative probability of a second cancer for patients who received radiotherapy was nearly twice that for patients who did not receive radiotherapy. Acute leukemia or myelodysplasia accounted for the majority of second cancers in the radiotherapy group. The risk of secondary acute leukemia is associated with the use of alkylating chemotherapy 32,33 and especially with the dose of mechlorethamine. ${ }^{34}$ The risk of leukemia is not increased after radiotherapy alone, ${ }^{35,36}$ but radiotherapy may increase the risk of leukemia if it is given after chemotherapy. ${ }^{37,38}$ This issue remains controversial. ${ }^{33-39}$ To date, 12 of our patients have had a solid tumor within the radiation field. Since the risk of solid tumors is expected to increase after radiotherapy, however, radiotherapy should be avoided whenever possible. Combination therapy with doxorubicin, bleomycin, vinblastine, and dacarbazine (ABVD), by contrast, is associated with a low rate of second cancers. ${ }^{40}$

In conclusion, we found that there is no need for involved-field radiotherapy to maintain remission in patients with stage III or IV Hodgkin's lymphoma who are in complete remission after six to eight cycles of MOPP-ABV hybrid chemotherapy. The only patients who benefit from radiotherapy are those in partial remission after chemotherapy.

Support for data evaluation was provided by the Ank van Vlissingen Foundation, the Netherlands.

This article is dedicated to J. Marion V. Burgers, radiation oncologist at the Netherlands Cancer Institute, Amsterdam, who was involved in the initiation of the trial and who died in 1997.

We are indebted to Peter Mauch, M.D., Ph.D., Harvard Medical School, for his suggestions and careful review and editing of the text.

A P PENDIX

In addition to the authors, the following investigators participated in the study: Algemeen Ziekenhuis Middelheim, Antwerp, Belgium - P. Meijnders; Institut Jules Bordet, Brussels, Belgium - P. van Houtte; Hôpital Universitaire Brugmann, Brussels, Belgium — M. Rauis; Hôpital Erasme, Brussels, Belgium — W. Feremans; University Hospital Gasthuisberg, Leuven, Belgium — Y. Lievens; Centre Hospitalier de Tivoli, La Louvière, Belgium — J. Michel; Institut Bergonié, Bordeaux, France - P. Richaud; Centre François Baclesse, Caen, France - A. Tanguy; Centre Hospitalier Général, Compiègne, France - P. Naccache and D. Zylberait; Hôpital Edouard Herriot, Lyons, France - D. Assouline; Centre Antoine Lacassagne, Nice, France - P.-Y. Bondiali and A. Thyss; Hôpital Necker-Enfants Malades, Paris - C. Bélanger; Hôtel Dieu, Paris - C.M. Blanc and A. Delmer; Hôpital Cochin, Paris F. Dreyfus; C.M.C. Foch, Suresnes, France - E. Baumelou; Centre Alexis Vautrin, Vandoeuvre les Nancy, France - T. Conroy; Institut Curie, Paris - J.M. Cosset; Zentralkankenhaus, Bremen, Germany — C.R. Meier; Clinica Sedes Sapientiae, Turin, Italy — R. Musella; Collegium Medicum Uniwersytet Jagiellonski, Krakow, Poland - W. Jurczak and J. Korzeniowski; Instituto Portugues de Oncologia, Porto, Portugal — E. Ferreira and E.F. Vieira; Medisch Centrum Alkmaar, Alkmaar, the Netherlands - E.H.J.M. Rutten and L.H. Siegenbeek van Heukelom; Academic Medical Center, Amsterdam — F. Oldenburger; Onze Lieve Vrouwe Gasthuis, Amsterdam - K.J. Roozendaal; Slotervaartziekenhuis, Amsterdam — M. Soesan; Ziekenhuis Hilversum, Hilversum, the Netherlands - S. Lobatto; Ziekenhuis Gooi Noord, Blaricum, the Netherlands - H.P. Muller; St. Ignatius Ziekenhuis, Breda, the Netherlands - G.J. Goverde; Bosch Medicentrum, 's Hertogenbosch, the Netherlands - H.A.M. Sinnige; Leyenburg Hospital, Den Haag, the Netherlands — W.B.J. Gerrits 
and J.A.L. Metsaars; Catharina Ziekenhuis, Eindhoven, the Netherlands - G.J. Creemers; Atrium Medisch Centrum Heerlen, Heerlen, the Netherlands M.M. Fickers; Academisch Hospital Maastricht, Maastricht, the Netherlands - P. Hupperets; St. Radiotherapeutisch Instituut Limburg, Heerlen, the Netherlands - T.A.M. Verschueren; Medisch Centrum Leeuwarden, Leeuwarden, the Netherlands - P. Joosten; University Medical Center Leiden, Leiden, the Netherlands - E.M. Noordijk; Erasmus Medical Center, Daniel den Hoed Cancer Center, Rotterdam, the Netherlands - M.J.J. Olofsen-van Acht; Bernard Verbeeten Instituut, Tilburg, the Netherlands - P.M.P. Poortmans; Streekziekenhuis Koningin Beatrix, Winterswijk, the Netherlands - A.J.M. Nielander; Sophia Ziekenhuis, Zwolle, the Netherlands - T.L.S.A. van Beek and M. van Marwyk Kooy.

The following were members of the pathology-review committee: Centre François Baclesse, Caen, France - A.-M. Mandard and J. Marnay (data manager); Institut Gustave Roussy, Villejuif, France - J. Bosq; Hôtel Dieu, Paris — J. Diebold; Netherlands Cancer Institute, Amsterdam — D. de Jong; St. James University Hospital, Leeds, United Kingdom - K.A. MacLennan; and British National Lymphoma Investigation — M.H. Bennett (deceased).

REFERENCES

1. Klimo P, Connors JM. MOPP/ABV hybrid program: combination chemotherapy based on early introduction of seven effective drugs for advanced Hodgkin's disease. J Clin Oncol 1985;3:1174-82.

2. Canellos GP, Anderson JR, Propert KJ, et al. Chemotherapy of advanced Hodgkin's disease with MOPP, ABVD, or MOPP alternating with ABVD. N Engl J Med 1992;327: 1478-84.

3. Somers R, Carde P, Henry-Amar M, et al. A randomized study in stage IIIB and IV Hodgkin's disease comparing eight courses of MOPP versus an alteration of MOPP with ABVD: a European Organization for Research and Treatment of Cancer Lymphoma Cooperative Group and Groupe Pierreet-Marie-Curie controlled clinical trial. J Clin Oncol 1994;12:279-87.

4. Raemaekers J, Burgers M, Henry-Amar M, et al. Patients with stage III/IV Hodgkin's disease in partial remission after MOPP/ABV chemotherapy have excellent prognosis after additional involved-field radiotherapy: interim results from the ongoing EORTC-LCG and GPMC phase III trial. Ann Oncol 1997; 8:Suppl 1:111-4.

5. Diehl V, Franklin J, Hasenclever D, et al BEACOPP, a new dose-escalated and accelerated regimen, is at least as effective as COPP/ABVD in patients with advanced-stage Hodgkin's lymphoma: interim report from a trial of the German Hodgkin's Lymphoma Study Group. J Clin Oncol 1998;16:3810-21. 6. Loeffler M, Brosteanu O, Hasenclever D et al. Meta-analysis of chemotherapy versus combined modality treatment trials in Hodg kin's disease. J Clin Oncol 1998;16:818-29. 7. GlickJH, Young ML, Harrington D, et al MOPP/ABV hybrid chemotherapy for advanced Hodgkin's disease significantly improves failure-free and overall survival: the 8-year results of the intergroup trial. J Clin Oncol 1998;16:19-26.

8. Horning SJ, Williams J, Bartlett NL, et al. Assessment of the Stanford V regimen and consolidative radiotherapy for bulky and advanced Hodgkin's disease: Eastern Cooperative Oncology Group pilot study E1492. J Clin Oncol 2000;18:972-80.

9. Fermé C, Sebban C, Hennequin C, et al. Comparison of chemotherapy to radiother apy as consolidation of complete or good partial response after six cycles of chemotherapy for patients with advanced Hodgkin's disease: results of the Groupe d'Etudes des Lymphomes de l'Adulte H89 trial. Blood 2000;95:2246-52.
10. Canellos GP, Niedzwiecki D. Long-term follow-up of Hodgkin's disease trial. N Eng J Med 2002;346:1417-8.

11. Yahalom J, Ryu J, Straus DJ, et al. Impact of adjuvant radiation on the patterns and rate of relapse in advanced-stage Hodgkin's dis ease treated with alternating chemotherapy combinations. J Clin Oncol 1991;9:2193 201.

12. Pavlovsky S, Santarelli MT, Muriel FS et al. Randomized trial of chemotherapy versus chemotherapy plus radiotherapy for stage III-IV A \& B Hodgkin's disease. Ann Oncol 1992;3:533-7.

13. Diehl V, Loeffler M, Pfreundschuh M et al. Further chemotherapy versus low-dose involved-field radiotherapy as consolidation of complete remission after six cycles of alternating chemotherapy in patients with advance Hodgkin's disease. Ann Oncol 1995 6:901-10.

14. Fabian CJ, Mansfield CM, Dahlberg S, et al. Low-dose involved field radiation afte chemotherapy in advanced Hodgkin's dis ease: a Southwest Oncology Group random ized study. Ann Intern Med 1994;120:903-12 15. Coleman M, Rafla S, Propert KJ, et al Augmented therapy of extensive Hodgkin's disease: radiation to known disease or pro longation of induction chemotherapy did not improve survival - results of a Cancer and Leukemia Group B study. Int J Radiat Onco Biol Phys 1998;41:639-45.

16. Nachman JB, Sposto R, Herzog P, et al. Randomized comparison of low-dose in volved-field radiotherapy and no radiotherapy for children with Hodgkin's disease who achieve a complete response to chemotherapy. J Clin Oncol 2002;20:3765-71.

17. Hancock SL, Hoppe RT. Long-term complications of treatment and causes of mortality after Hodgkin's disease. Semin Radia Oncol 1996;6:225-42.

18. Henry-Amar M, Hayat M, Meerwaldt JH, et al. Causes of death after therapy for early stage Hodgkin's disease entered on EORTC protocols. Int J Radiat Oncol Biol Phys 1990 19:1155-7.

19. Ng AK, Bernardo MP, Weller E, et al. Long-term survival and competing causes of death in patients with early-stage Hodgkin's disease treated at age 50 or younger. J Clin Oncol 2002;20:2101-8.

20. Swerdlow AJ, Barber JA, Hudson GV, et al. Risk of second malignancy after Hodg kin's disease in a collaborative British cohort: the relation to age at treatment. J Clin Oncol 2000;18:498-509.
21. van Leeuwen FE, Klokman WJ, Veer MB, et al. Long-term risk of second malignancy in survivors of Hodgkin's disease treated during adolescence or young adulthood. J Clin Oncol 2000;18:487-97.

22. Yuen AR, Rosenberg SA, Hoppe RT, Halpern JD, Horning SJ. Comparison between conventional salvage therapy and high-dose therapy with autografting for recurrent or refractory Hodgkin's disease. Blood 1997;89:814-22.

23. Sureda A, Arranz R, Iriondo A, et al. Autologous stem-cell transplantation for Hodgkin's disease: results and prognostic factors in 494 patients from the Grupo Espanol de Linfomas/Transplante Autologo de Medula Osea Spanish Cooperative Group. J Clin Oncol 2001;19:1395-404

24. Fermé C, Mounier N, Divine M, et al. Intensive salvage therapy with high-dose chemotherapy for patients with advanced Hodgkin's disease in relapse or failure after initial chemotherapy: results of the Groupe d'Etudes des Lymphomes de l'Adulte H89 Trial. J Clin Oncol 2002;20:467-75

25. DeVita VT Jr, Simon RM, Hubbard SM, et al. Curability of advanced Hodgkin's disease with chemotherapy: long-term followup of MOPP-treated patients at the National Cancer Institute. Ann Intern Med 1980;92: 587-95.

26. Lee CK, Bloomfield CD, Goldman AI, Levitt SH. Prognostic significance of mediastinal involvement in Hodgkin's disease treated with curative radiotherapy. Cancer 1980;46:2403-9.

27. Dixon DO, McLaughlin P, Hagemeister FB, et al. Reporting outcomes in Hodgkin's disease and lymphoma. J Clin Oncol 1987;5: $1670-2$

28. Dose specifications for reporting external beam therapy with photons and electrons. ICRU report 29. Bethesda, Md.: International Commission on Radiation Units and Measurements, 1978.

29. Rothman KJ, Boice JD Jr. Epidemiologic analysis with a programmable calculator. Boston: Epidemiology Resources, 1982.

30. Stata statistical software, release 7.0 College Station, Tex.: Stata, 2001.

31. Wartelle M, Kramar A, Jan P, et al. "PIGAS": an interactive statistical database management system. In: Hammond R, McCarthy JL, eds. Proceedings of the Second International Workshop on Statistical Database Management. Springfield, Va.: National Technical Information Service, Department of Commerce, 1983. 


\section{RADIOTHERAPY IN ADVANCED HODGKIN'S LYMPHOMA}

32. Pedersen-Bjergaard J, Specht L, Larsen $\mathrm{SO}$, et al. Risk of therapy-related leukaemia and preleukaemia after Hodgkin's disease: relation to age, cumulative dose of alkylating agents, and time from chemotherapy. Lancet 1987;2:83-8.

33. Kaldor JM, Day NE, Clarke EA, et al. Leukemia following Hodgkin's disease. N Engl J Med 1990;322:7-13.

34. van Leeuwen FE, Chorus AM, van den Belt-Dusebout AW, et al. Leukemia risk following Hodgkin's disease: relation to cumulative dose of alkylating agents, treatment with teniposide combinations, number of episodes of chemotherapy, and bone marrow damage. J Clin Oncol 1994;12:1063-73.
35. Swerdlow AJ, Douglas AJ, Hudson GV, Hudson BV, Bennett MH, MacLennan KA. Risk of second primary cancers after Hodgkin's disease by type of treatment: analysis of 2846 patients in the British National Lymphoma Investigation. BMJ 1992;304:1137

43.

36. Tucker MA, Coleman CN, Cox RS, Varghese A, Rosenberg SA. Risk of second cancers after treatment for Hodgkin's disease. N Engl J Med 1988;318:76-81.

37. Mauch PM, Canellos GP, Rosenthal DS Hellman S. Reduction of fatal complications from combined modality therapy in Hodgkin's disease. J Clin Oncol 1985;3:501-5.

38. Henry-Amar M. Second cancer after the treatment for Hodgkin's disease: a report from the International Database on Hodgkin's Disease. Ann Oncol 1992;3:Suppl 4: 117-28.

39. Swerdlow AJ, Barber JA, Horwich A, Cunningham D, Milan S, Omar RZ. Second malignancy in patients with Hodgkin's disease treated at the Royal Marsden Hospital. Br J Cancer 1997;75:116-23.

40. Duggan DB, Petroni GR, Johnson JL, et al. Randomized comparison of ABVD and MOPP/ABV hybrid for the treatment of advanced Hodgkin's disease: report of an intergroup trial. J Clin Oncol 2003;21:60714

Copyright @ 2003 Massachusetts Medical Society. 